http://jmscr.igmpublication.org/home/

ISSN (e)-2347-176x ISSN (p) 2455-0450

crossref DOI: https://dx.doi.org/10.18535/jmscr/v8i11.43

\title{
A Rare Case of Acute Paraplegia: Granulocytic Sarcoma- Case Report
}

\author{
Authors \\ Dr Dhivya $\mathrm{C}^{1}$, Dr Aswinth M.D. ${ }^{2}$ \\ ${ }^{1}$ Post Graduate, Department of General Medicine, Rajah Muthiah Medical College \& Hoapital, Annamalai \\ University, Chidambaram, India -608002 \\ ${ }^{2}$ Assistant Professor, Department of General Medicine, Rajah Muthiah Medical College \& Hoapital, \\ Annamalai University, Chidambaram, India -608002
}

\begin{abstract}
Granulocytic sarcoma (GS) or also known as choloroma, myeloblastoma, myelosarcoma, is an uncommen extramedullary solid tumor of immature myeloid cells. The term 'chloroma' was given by King due to the green appearance which is produced by the presence of myeloperoxidase granules in the malignant myeloid cells in 1853. It could occur in anywhere in the body, soft tissues or lymph node rarely involving central nervous system and leading to spinal cord compression, in association with AML. It could occur during the course of disease, or at relapse, or as isolated granulocytic sarcoma (IGS). We report a case of 18 years old boy presented with paraplegia, diagnosed as Granulocytic sarcoma associated with Acute Myeloid Leukemia.
\end{abstract}

\section{Introduction}

Granulocytic sarcoma (GS) is a rare extramedullary tumor made of immature myeloid cells. The choloroma may be the initial presentation of leukemia and can occur in different anatomic sites. Spinal myeloid sarcoma is uncommen, and spinal cord compression caused by myeloid sarcoma is even more so $^{(1)}$. The incidence of myeloid sarcoma is $2.5-9.1 \%$ of AML patients. And the incidence of MS in non leukemic patient is $1.8 \%$.This study reports a rare case of spinal myeloid sarcoma presenting as paraplegia. He was treated with chemo-irradiation.

\section{Case Report}

An 18 year old adolescent boy presented to us with progressively worsening back pain for 2 months. It was dull aching and continuous, not radiating. His condition worsened to weakness of bilateral lower limb. There is no history of trauma to back, no consanguinity of parents, neither family history of malignancy nor similar condition. He neither had previous medical nor surgical problems. On examination patient looks emaciated. Patient conscious, oriented, febrile ( $\mathrm{T}$ $100 \mathrm{C}$ ), hydration - fair, pallor present, bilateral cervical, b/l axillary and $b / 1$ inguinal lymphadenopathy present. Gym hypertrophy is seen. Sternal tenderness present. On systemic examination, no organomegaly. Motor system power $-3 / 5$,sensation and proprioception impaired in bilateral lower limbs. 
His investigations are as follows:

Table-1: Investigation Chart

\begin{tabular}{|l|c|}
\hline $\mathrm{Hb}$ & 5.5 \\
\hline $\mathrm{TC}$ & 14000 \\
\hline Pl.Ct & 20000 \\
\hline RBS & 98 \\
\hline Urea & 30 \\
\hline Sr.Cr & 0.7 \\
\hline Na+ & 137 \\
\hline K+ & 4.8 \\
\hline Cl- & 99 \\
\hline T.Bilirubin & 0.9 \\
\hline D.Bilirubin & 0.2 \\
\hline SGOT & 62 \\
\hline SGPT & 48 \\
\hline ALP & 298 \\
\hline Albumin & 3.4 \\
\hline Globulin & 3.0 \\
\hline CPK & 41 \\
\hline
\end{tabular}

Fig-1: Acute Myelogenous Leukemia (AML)

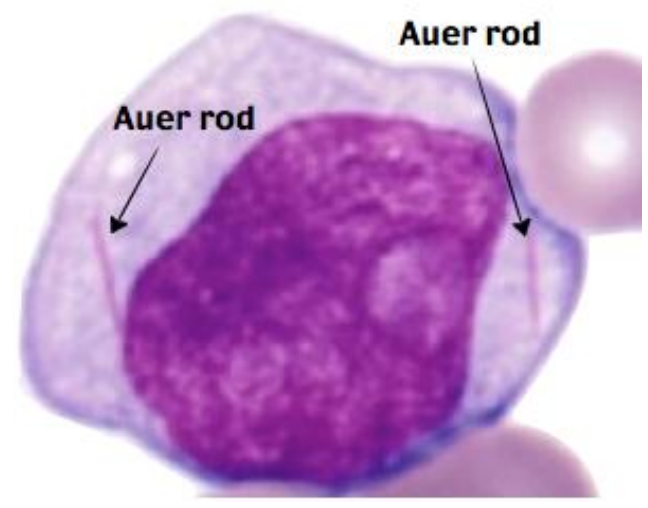

Complete blood picture - TC: 14,000cells/cu mm, out of which Blasts 23\%, Few Auer rods seen. Flow cytometry: CD33 /HLA DR / CD11 / CD13 / CD117 / MPO +ve; MRI Spine (10/05)-showed leukemic infiltrates of spine L1, L2. Patient received RT to L1, L2 spine $20 \mathrm{GY} / 10 \#$ from $13 / 05$ to $28 / 05$. Patient was given Induction therapy with standard 3/7 DNR (daunorubicin 75 $\mathrm{mg}$ ) + Ara-C (cytarabine 62mg) and 1st Consolidation HIDAC Ara-C $09 \mathrm{gm} / \mathrm{m} 2 \times 3$ days. $2^{\text {nd }}$ Consolidation HIDAC Ara-C $18 \mathrm{mg} / \mathrm{m} 2 \times 3$ days followed by $3^{\text {rd }}$ Consolidation HIDAC AraC $18 \mathrm{gm} / \mathrm{m} 2 \times 3$ days. Patient further developed pain in the sacral region, along with urinary and fecal incontinence, blurring of vision in left eye.MRI (01/09) showed multiple site choloromas involving left eye along with large presacral mass of size $10 \times 6.5 \times 5 \mathrm{~cm}$. For which RT given from
T5-T9 and Sacral lesion 18GY/6\#.In addition to above management, he was treated with antibiotics, steroids, repeated blood transfusions and other supportive care. Despite above efforts, patient condition detoriated, he could not be revived and declared dead.

Fig-2: Patient with left granulocytic sarcoma

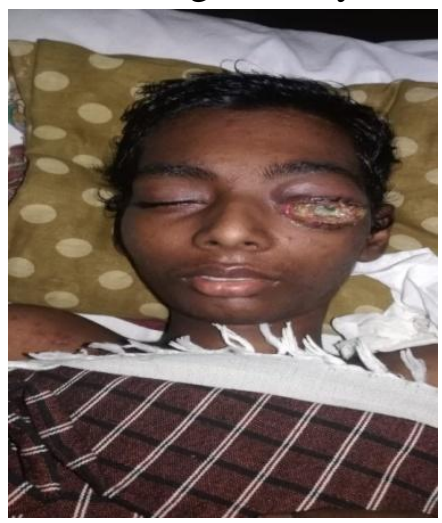

\section{Discussion}

A myeloid sarcoma or chloroma or also known as granulocytic sarcoma is a rare, extra medullary myeloid tumor. It is a solid tumor made of immature granulocytes ${ }^{[2]}$. It is a rare hematologic phenomenon in AML with an incidence as low as 2.5 to $9.1 \%$. It may occur during the course of disease or just preceding the disease course or following the course of leukemia. Myeloid sarcoma has a increased predilection for males (male-to-female ratio, 1.2:1) ${ }^{[3]}$.

The commonly involved sites include the skin, the lymph nodes, gastrointestinal tract, bones, soft tissue, and testis. ${ }^{[4]}$ However, spinal cord involvement of granulocytic sarcoma is even less than 1 percent ${ }^{[5]}$.

Spinal myeloid sarcoma can present with varied symptoms depending upon the site of sarcoma. Some cases present with involvement of paraspinal muscles may lead to spinal cord compression due to mass effect ${ }^{[1]}$. In the case discussed here, patient initially presented with progressively increasing back pain that leading to paraplegia. Spinal myeloid sarcoma is often difficult to diagnose because of the varying clinical data and imaging which is usually nonspecific. It often appears as a soft tissue mass 
on computed tomography or MRI that most of the time does not point to a specific diagnosis ${ }^{[5]}$. Hence, it is crucial to obtain a tissue biopsy to make out a diagnosis of myeloid sarcoma. Following biopsy, multiple investigations like immunohistochemistry and a series of markers is a practical guide that aids in the diagnosis and further characterization of the tumor ${ }^{[6]}$.

Given the rare incidence of spinal myeloid sarcomain AML, the clinical suspicion of the disease should be kept high so that the treatment can start at optimal timing for better outcome. Possible treatment strategies include chemotherapy, hematopoietic stem cell transplantation (HSCT), radiotherapy and surgery has been proposed. Systemic chemotherapy used in the treatment of AML remains the best strategy for treating this set of patients. Surgery is however limited to the cases with symptomatic compression due to the tumor ${ }^{[7]}$.

Inoue et al identified 26 patients of spinal myeloid sarcoma from various literature whose treatment strategy varied from individual to individual. Overall, prompt diagnosis and adequate treatment are critical to achieve a better outcome.

\section{Conclusion}

Acute Myeloid Leukemia presenting as Granulocytic Sarcoma is relatively uncommon. Spinal myeloid sarcoma in AML presenting as paraplegia is very rare. Clinical suspicion of the disease can lead to early diagnosis and appropriate management at the right time. Keeping in view of literature, we suggest that prompt diagnosis followed by curative rathiotheraphy and intensive chemotherapy in the line of management of AML can lead to complete recovery objectively and clinically and can prevent neurological damage.

\section{References}

1. Hu X, Shahab I, Lieberman IH. Spinal Myeloid Sarcoma "Chloroma" Presenting as Cervical Radiculopathy: Case Report. Global Spine J. 2015; 5: 241-246.
2. Karlin L, Itti E, Pautas C, Rachid M, Bories D, Cordonnier C, et al. "PETimaging as a useful tool for early detection of the relapse site in the management of primary myeloid sarcoma". Haematologica. 2006; 91: (12 Suppl): EcR54.

3. Pileri SA, Ascani S, Cox MC, Campidelli C, Bacci F, Piccioli M, et al. Myeloid sarcoma: clinico-pathologic, phenotypic and cytogenetic analysis of 92 adult patients. Leukemia. 2007; 21: 340-350.

4. Seifert RP, Bulkeley W, Zhang L, Menes M, Bui MM. A practical approach to diagnose soft tissue myeloid sarcoma preceding or coinciding with acute myeloid leukemia. Ann Diagn Pathol. 2014; 18: 253-260.

5. Seok J H, Park J, Kim S K, Choi J E, Kim C C. Granulocytic sarcoma of the spine: MRI and clinical review. AJR Am J Roentgenol. 2010; 194: 485-489.

6. Campidelli C, Agostinelli C, Stitson R, Pileri SA. Myeloid sarcomextramedullary manifestation of myeloid disorders. Am J Clin Pathol. 2009; 132: 426-437.

7. Cheah KL, Lim LC, Teong HH, Chua SH. A case of generalized cutaneous granulocytic sarcoma in an elderly patient with myelodysplastic syndrome. Singapore Med J. 2002; 43: 527-529. 